\title{
Comparison of paroxetine and agomelatine in depressed type 2 diabetes mellitus patients: a double-blind, randomized, clinical trial
}

This article was published in the following Dove Press journal:

Neuropsychiatric Disease and Treatment

27 May 2015

Number of times this article has been viewed

\section{Ruiying Kang' \\ Yan $\mathrm{He}^{\prime}$ \\ Yuxiang Yan' \\ Zhiwu $\mathrm{Li}^{2}$ \\ Yeqing $\mathrm{Wu}^{3}$ \\ Xiaojuan $\mathrm{Guo}^{4}$ \\ Zhigang Liang ${ }^{5}$ \\ Jun Jiang ${ }^{2}$}

'Department of Epidemiology and Biostatics, School of Public Health, Capital Medical University, Beijing, People's Republic of China; ${ }^{2}$ Fengtai Nanyuan Hospital of Beijing, Beijing, People's Republic of China; ${ }^{3}$ Fengtai District Community Health Center, Beijing, People's Republic of China; ${ }^{4}$ Department of Preventive Medicine, School of Environmental and Public Health, Wenzhou Medical University, Wenzhou, People's Republic of China; ${ }^{5}$ Xuanwu Hospital, Capital Medical University, Beijing, People's Republic of China
Correspondence: Yan $\mathrm{He}$

Department of Epidemiology and Biostatics, School of Public Health, Capital Medical University, No I0, Xitoutiao, Youanmenwai Street, Fengtai District, 100069, Beijing, People's

Republic of China

$\mathrm{Tel}+86108391 \quad 1000$

Fax +86 I0I 839I 1029

EmailYHYanHe@163.com
Background: Comorbid depression/anxiety in type 2 diabetes mellitus (DM) patients is highly prevalent, affecting both diabetes control and quality of life. However, the best treating method for depression/anxiety in type 2 DM patients is still unclear. This study was conducted to compare the efficacy of paroxetine and agomelatine on depression/anxiety and metabolic control of type $2 \mathrm{DM}$ patients.

Methods: A total of 116 depressed, type 2 DM patients were recruited for 12 weeks treatment. Patients were randomly assigned to receive either paroxetine or agomelatine. Hamilton Depression Rating Scale and Hamilton Anxiety Rating Scale were used to assess depression and anxiety, respectively. Hemoglobin A1c, fasting plasma glucose, and body mass index were assessed at baseline and at the end of the trial.

Results: At the end of the trial, there were 34 (60.7\%) responders and 22 (39.3\%) remissions in paroxetine group; and $38(63.3 \%)$ responders and $26(43.3 \%)$ remissions in agomelatine group. Compared to paroxetine group, lower depression scores were observed in agomelatine group. Fasting plasma glucose and body mass index were not significantly different after 12 weeks treatment between the two groups, but agomelatine group had a significantly lower final hemoglobin A1c level compared to paroxetine group. The two antidepressants had comparable acceptability.

Conclusion: These results showed that compared to paroxetine, agomelatine might have some advantages in treating symptoms of depression/anxiety and glycemic control in depressed type 2 DM patients. The clinical applicability of agomelatine shows greater promise and should be explored further. Limited by the relatively small samples, future studies are needed to verify and support our findings.

Keywords: paroxetine, agomelatine, depression, diabetes mellitus

\section{Introduction}

Type 2 diabetes mellitus (DM) is a common disease that is characterized by impaired insulin secretion and insulin resistance, and rapidly increasing prevalence worldwide. ${ }^{1,2}$ Previous studies have shown that psychiatric disorders frequently occur in type 2 DM patients, and about $15 \%$ of the diabetes patients are comorbid with depression. ${ }^{3-5}$ Moreover, rates coming to more than $20 \%$ have been reported for life-long prevalence of depression. ${ }^{6,7}$ Depression may have a role in the pathogenesis of DM. One study reported that the biochemical changes in depressed patients stimulated the hypothalamic-pituitary-adrenal axis, which resulted in increased cortisol level and blood glucose, eventually progressing to diabetes. ${ }^{8}$ On the other hand, if not effectively and timely treated, depression will increase the rates of complications ${ }^{9}$ and produce negative effects on glucose regulation. ${ }^{10}$ Currently, due to lack of objective test for 
diagnosing depression, depression is often undiagnosed and untreated in diabetes patients. ${ }^{11}$ Nowadays, more and more researchers use metabonomics to identify diagnostic biomarkers for neuropsychiatric disorders, ${ }^{12-14}$ which will be helpful for the development of objective test. Meanwhile, researchers have evaluated the effects of antidepressant therapies on glycemic control in diabetes patients. ${ }^{15,16}$ Some selective serotonin reuptake inhibitors (SSRIs) are found to have good effect on the treatment of insulin resistance and be well tolerated. Fluoxetine could promote weight loss to improve insulin sensitivity and lower blood glucose levels in patients with type 2 DM. ${ }^{15-17}$ Paroxetine is an antidepressant that can selectively block serotonin reuptake, but cause little effect on dopamine and norepinephrine reuptake. It is primarily used to treat psychiatry disorders. Meanwhile, paroxetine could effectively reduce the severity of major depressive disorder in type 2 DM patients, ${ }^{18}$ and one study showed that paroxetine could yield positive effects on measures of insulin sensitivity and might improve glycemic control. ${ }^{19}$ Agomelatine, as a melatonergic antidepressant, is marketed for the treatment of depression. Compared to SSRIs, it causes less or no sexual side effects and discontinuation syndrome. Also, agomelatine appears to improve sleep quality. Recently, agomelatine was reported to have better effects on the symptoms of depression/ anxiety, metabolic parameters, and health-related behaviors in type 2 DM patients with depression than sertraline. ${ }^{20}$

Whether different antidepressants show different effects on psychological symptoms and metabolic control in type 2 DM patients is still unknown, and the best treating method for depression/anxiety is still unclear. Therefore, we conducted this work to compare the efficacy of agomelatine and paroxetine on the symptoms of depression/anxiety, level of blood sugar, and endocrine hormones in depressed type 2 DM patients.

\section{Methods}

\section{Patients}

Type 2 DM patients with depression were recruited from Beijing Mental Health Information Management System (BMHIMS) in Fengtai District (Beijing, People's Republic of China) between January 2012 and December 2014. This work was reviewed and approved by the Ethical Committee of Capital Medical University. The methods were carried out in accordance with the approved guidelines and regulations. At first, patients were evaluated by endocrinologists for DM. Values of hemoglobin A1c $\left(\mathrm{HbA}_{1 \mathrm{c}}\right)>7 \%$ were considered acceptable. Then, patients were evaluated by psychiatrists for depression using Diagnostic and Statistical Manual of Mental Disorders, Fourth edition (DSM-IV). Patients with a score of $\geq 17$ on the Hamilton Depression Rating Scale (HDRS) were admitted into the study. The body mass index (BMI) was calculated as body weight $(\mathrm{kg})$ divided by the square of the height $\left(\mathrm{m}^{2}\right)\left(\mathrm{kg} / \mathrm{m}^{2}\right)$. Additionally, patients were excluded from the study if they: 1) displayed active suicidal ideation; 2) had serious mental or physical disease; 3) had a history of any other psychiatric disorders; 4) were currently under psychoactive medications treatment. All patients provided written informed consent before the treatment and were under standard treatment for diabetes by an endocrinologist. Finally, a total of 116 depressed, type 2 DM patients, aged 27-73 years were recruited.

\section{Study design}

Type 2 DM patients meeting inclusion criteria were randomly assigned to receive $20-40 \mathrm{mg}$ /day paroxetine or $30-50 \mathrm{mg}$ /day agomelatine. We used a separate computer-generated random number sequence to do randomization. The allocation ratio was about 1:1, assigning 56 patients to paroxetine group and 60 patients to agomelatine group. Patients and raters were blinded to the treatments. HDRS and Hamilton Anxiety Rating Scale (HARS) scores were assessed before the treatment, at the end of 6 and 12 weeks. Same interviewer who was blinded to the study design completed the HDRS and HARS scale assessments. Before the treatment and at the end of the trial, $\mathrm{HbA}_{1 \mathrm{c}}$, fasting plasma glucose (FPG), and BMI were assessed. Medication at constant doses was given during the whole treatment period. Treatment methods were changed, such as increasing medicine doses, using or combining with another antidepressant, for patients who did not meet response criteria at the end of the trial.

\section{Outcome measurement}

Patients' basic data, such as age, sex, education, smoking history, and alcohol intake were recorded. HDRS and HARS scores were used to assess the symptoms of depression and anxiety, which were considered as the primary outcomes of this study, whilst other parameters were considered as the secondary outcomes. Response was defined as at least a 50\% reduction in the absolute HDRS score. Remission was defined as posttreatment HDRS score $\geq 7$. The number of patients withdrawn from study and adverse events in two groups were used to assess the acceptability of paroxetine and agomelatine.

\section{Statistical analyses}

Data were gathered at predetermined time points. For continuous data, the mean and standard deviation (SD) were used. For dichotomous data, the number and percentage were used. Analysis for HARS and HDRS scores, $\mathrm{HbA}_{1 \mathrm{c}}$, 
FPG, and BMI was conducted using analysis of covariance (ANCOVA). This method could examine the effect of treatment (factor) on the parameters' values at the last assessment, covarying out the effect of each parameter's initial value. ${ }^{21}$ The Bonferroni correction was taken into consideration for multiple comparisons. ${ }^{22}$ Student's $t$-test and chi-square test were used to do univariate analysis. Data analysis was performed using SPSS 19.0. All tests were two-sided with statistical significance set to a $P$-value of 0.05 .

\section{Results}

\section{Recruited patients}

This study recruited 116 type 2 DM patients with depression/ anxiety, composed of 56 patients in paroxetine group and 60 patients in agomelatine group. Average age of patients in paroxetine group and agomelatine group was $52.5 \pm 10.3$ years and 50.8 \pm 11.4 years, respectively. Average level of education in paroxetine and agomelatine group was $9.67 \pm 5.33$ years and $9.53 \pm 4.79$ years, respectively. The two groups also had no significant differences in terms of smoking history, sex, or alcohol intake. The initial mean scores of HDRS and HARS in two groups were no different. The detailed information is given in Table 1.

\section{Depression and anxiety}

The HDRS and HARS scores at the end of 6 and 12 weeks were not significantly related to their initial values, and were significantly decreased compared to the initial values. At the end of 6 weeks, the HDRS and HARS scores in agomelatine group were non-statistically significantly lower compared with paroxetine group. But at the end of 12 weeks, the HARS score in agomelatine group were significantly lower compared with paroxetine group. After 6 weeks' treatment, overall 49 patients $(42.2 \%)$ met response criteria. Of these, 23 patients responded $(23 / 56,41.1 \%)$ to paroxetine treatment and 26 patients responded $(26 / 60,43.3 \%)$ to agomelatine treatment $(P=0.81)$. With regard to remission, 28 patients $(24.1 \%)$ met remission criteria, composed of 13 patients $(13 / 56$, $23.2 \%)$ in paroxetine group and 15 patients $(15 / 60,25.0 \%)$ in agomelatine group $(P=0.82)$. At the end of 12 weeks, the number of responders in paroxetine and agomelatine group was $34(60.7 \%)$ and $38(63.3 \%)$, respectively $(P=0.60)$. The number of remissions in paroxetine and agomelatine group was $22(39.3 \%)$ and $26(43.3 \%)$, respectively $(P=0.66)$.

\section{Metabolic control}

The final $\mathrm{HbA}_{1 \mathrm{c}}, \mathrm{FPG}$, and BMI were significantly related to their initial values. At the end of the trial, there were no statistically significant differences between the two groups in FPG and BMI (Table 2). ANCOVA was conducted to test the effect of treatment on post-treatment $\mathrm{HbA}_{1 \mathrm{c}}, \mathrm{FPG}$, and BMI, using their pretreatment values as the covariate. The results showed that the effect of treatment on FPG and BMI was not significant, but the effect of treatment on $\mathrm{HbA}_{1 \mathrm{c}}$ was significant. The average level of $\mathrm{HbA}_{1 \mathrm{c}}$ was significantly lower in agomelatine group compared with paroxetine group after 12 weeks treatment. Additionally, there was no significant difference in post-treatment $\mathrm{HbA}_{1 \mathrm{c}}$ level between responders and non-responders.

\section{Acceptability analyses}

Both paroxetine and agomelatine were well tolerated. And all the patients completed the trial. The most commonly reported adverse events in the two groups were anxiety and insomnia. There was no significant difference in adverse events between paroxetine group and agomelatine group. Treatment-related adverse events in the two groups are recorded in Table 3.

\section{Discussion}

This study found that paroxetine and agomelatine had a similar efficacy on the management of depression and anxiety in type 2 DM patients. At the end of the trial, depressive and anxiety symptoms of patients in the two groups were significantly decreased. Compared to depression, the decreased level of anxiety in paroxetine group started later. This might be explained by a fact that the SSRIs lead to some increase in anxiety level at the early stages of treatment. ${ }^{18}$ After 12 weeks treatment, the two antidepressants (paroxetine vs agomelatine) had the similar response rates $(60.7 \%$ vs $63.3 \%)$ and remission rates $(39.3 \%$ vs $43.3 \%)$. Notably, considering the treatmentresistant nature of depression in some patients, an impressive $43.3 \%$ remission rate clearly indicated the clinical utility of agomelatine. Although there were some adverse events, both

Table I Demographic of included patients

\begin{tabular}{|c|c|c|c|c|c|c|}
\hline & Number & $\operatorname{Sex}(F / M)$ & $\begin{array}{l}\text { Age, years } \\
\text { (mean/SD) }\end{array}$ & $\begin{array}{l}\text { Education, years } \\
\text { (mean/SD) }\end{array}$ & $\begin{array}{l}\text { Smoke } \\
\text { (n) }\end{array}$ & $\begin{array}{l}\text { Alcohol } \\
\text { (n) }\end{array}$ \\
\hline Paroxetine & 56 & $25 / 31$ & $52.50 \pm 10.27$ & $9.67 \pm 5.33$ & II & 8 \\
\hline Agomelatine & 60 & $28 / 32$ & $50.82 \pm 11.36$ & $9.53 \pm 4.79$ & 15 & 7 \\
\hline$t / \chi^{2}$ & NA & 0.048 & -0.67 & 0.83 & 0.48 & 0.18 \\
\hline$P$-value & NA & 0.83 & 0.50 & 0.84 & 0.49 & 0.67 \\
\hline
\end{tabular}

Abbreviations: $F$, female; $M$, male; NA, not applicable; SD, standard deviation. 
Table 2 Mean scores \pm SD of outcomes in paroxetine and agomelatine groups

\begin{tabular}{|c|c|c|c|c|c|c|}
\hline Outcomes & Group & Initial assessment & Six weeks & Final assessment & $t$ & $P$-value ${ }^{a}$ \\
\hline \multirow[t]{2}{*}{ HDRS } & Paroxetine & $23.94 \pm 3.07$ & $16.00 \pm 6.77$ & $10.50 \pm 4.33$ & 15.16 & $<0.0001$ \\
\hline & Agomelatine & $24.20 \pm 3.38$ & $|4.80 \pm 6.4|$ & $9.35 \pm 3.79$ & 18.45 & $<0.0001$ \\
\hline \multirow[t]{2}{*}{ HARS } & Paroxetine & $16.78 \pm 3.35$ & $13.8 \mid \pm 3.69$ & $8.56 \pm 2.62$ & 11.56 & $<0.0001$ \\
\hline & Agomelatine & $16.38 \pm 4.19$ & $12.48 \pm 3.19$ & $6.93 \pm 2.15$ & 12.68 & $<0.0001$ \\
\hline \multirow[t]{2}{*}{$\mathrm{HbA}_{\mathrm{Ic}}(\%)$} & Paroxetine & $7.7 I \pm 0.46$ & NA & $7.6 \mathrm{I} \pm 0.40$ & 0.92 & 0.376 \\
\hline & Agomelatine & $7.84 \pm 0.45$ & NA & $7.26 \pm 0.46$ & 5.56 & $<0.0001$ \\
\hline \multirow[t]{2}{*}{ FPG $(\mathrm{mmol} / \mathrm{L})$} & Paroxetine & $8.07 \pm 0.79$ & NA & $7.89 \pm 0.78$ & 0.97 & 0.209 \\
\hline & Agomelatine & $8.18 \pm 0.85$ & NA & $8.03 \pm 0.77$ & 0.85 & 0.333 \\
\hline \multirow[t]{2}{*}{ BMI $\left(\mathrm{kg} / \mathrm{m}^{2}\right)$} & Paroxetine & $25.91 \pm 3.31$ & NA & $27.19 \pm 3.45$ & -1.61 & 0.111 \\
\hline & Agomelatine & $25.63 \pm 4.18$ & NA & $24.74 \pm 3.46$ & 1.03 & 0.306 \\
\hline
\end{tabular}

Note: ${ }^{P}$-value was obtained by comparing the final assessment to the initial assessment.

Abbreviations: SD, standard deviation; HDRS, Hamilton Depression Rating Scale; HARS, Hamilton Anxiety Rating Scale; HbA BMI, body mass index; NA, not available.

paroxetine and agomelatine were well tolerated with none of the patients being withdrawn. And agomelatine was reported to cause fewer discontinuation syndrome and sexual side effects than paroxetine. The abovementioned results showed that agomelatine might be a promising agent in the treatment of depression and anxiety in depressed type 2 DM patients.

One previous study reported that depressed type 2 DM patients receiving agomelatine had a significantly lower final average $\mathrm{HbA}_{1 \mathrm{c}}$ level than patients receiving sertraline. ${ }^{20}$ Another study reported that sertraline could decrease the severity of depressive symptoms and $\mathrm{HbA}_{1 \mathrm{c}}$ level in a group of depressed type $2 \mathrm{DM}$ patients. ${ }^{23}$ Fluoxetine was very often used in depressed type 2 DM patients. Lustman et al reported that fluoxetine could effectively reduce the severity of depression and $\mathrm{HbA}_{1 \mathrm{c}}$ level in $\mathrm{DM}$ patients with depression. ${ }^{24}$ Another study found that fluoxetine and paroxetine could effectively reduce the severity of major depressive disorder in depressed type $2 \mathrm{DM}$ patients, and the improvement in the average $\mathrm{HbA}_{1 \mathrm{c}}$ level was greater in fluoxetine group than in paroxetine group. ${ }^{18}$ After being treated with paroxetine, a trend toward improvement was also found in mental health and glycemic control in mildly depressed women with type 2 $\mathrm{DM} .{ }^{25}$ In this study, we found that significantly lower final average $\mathrm{HbA}_{1 \mathrm{c}}$ level was measured in agomelatine group compared with paroxetine group. Moreover, our study also found that agomelatine was not associated with body weight gain, which might contribute to a better glycemic control. ${ }^{26}$
Life quality of diabetes patients was negatively affected by the comorbid depression and anxiety. ${ }^{27}$ But relatively few randomized control trials investigated the efficacy of antidepressants in diabetes patients. Due to the less antiadrenergic and anticholinergic side effects, SSRIs and other novel antidepressants were more acceptable and safer for diabetes patients with depression. A recently published metaanalysis found that the combination of pharmacotherapy and psychotherapy had a positive efficacy both for depressive symptoms and diabetes-related parameters. ${ }^{28}$ The significant antidepressant efficacy and favorable side effect profile of agomelatine were reported in a number of studies. ${ }^{29-31} \mathrm{In}$ this study, we found that agomelatine possibly offered some advantages over paroxetine in the treatment of symptoms of depression/anxiety and glycemic control.

Three limitations limit the generalizability of our findings: 1) the relatively small size of recruited patients; 2 ) the shortterm follow-up; and 3) the lack of a placebo control group. Therefore, longer-lasting monitoring studies with larger populations are needed to investigate which antidepressants would be the optimal choice to treat the symptoms of depression/ anxiety in depressed type $2 \mathrm{DM}$ patients, and evaluate the different metabolic parameters related to metabolic control. Overall, this study shows that agomelatine could significantly improve depression and have a positive effect on glycemic control. The clinical applicability of agomelatine shows greater promise and should be explored further.

Table 3 Treatment-related adverse events in paroxetine and agomelatine groups

\begin{tabular}{llllllll}
\hline & Nausea & Headache & Dry mouth & Diarrhea & Anxiety & Dizziness & Insomnia \\
\hline Paroxetine, $\mathrm{n}(\%)$ & $3(5.6 \%)$ & $2(3.6 \%)$ & $3(5.6 \%)$ & $2(3.6 \%)$ & $4(7.1 \%)$ & $2(3.6 \%)$ & $6(10.7 \%)$ \\
Agomelatine, $\mathrm{n}(\%)$ & $1(1.7 \%)$ & $2(3.3 \%)$ & $2(3.3 \%)$ & $1(1.7 \%)$ & $4(6.7 \%)$ & $3(5.0 \%)$ & $2(3.3 \%)$ \\
$\chi^{2}$ & 1.19 & 0.005 & 0.29 & 0.42 & 0.01 & 0.17 & 2.46 \\
$P$-value & 0.28 & 0.94 & 0.67 & 0.61 & 0.92 & 0.71 & 0.12 \\
\hline
\end{tabular}




\section{Conclusion}

Compared to paroxetine, agomelatine might have some advantages in treating symptoms of depression/anxiety and glycemic control in type $2 \mathrm{DM}$ patients comorbid with depression/anxiety. The clinical applicability of agomelatine shows greater promise and should be explored further. Our study was limited by the relatively small samples. Future studies are needed to verify and support our findings.

\section{Disclosure}

No financial support for this study was received. The authors report no conflicts of interest in this work.

\section{References}

1. Harris MI, Flegal KM, Cowie CC, et al. Prevalence of diabetes, impaired fasting glucose, and impaired glucose tolerance in US adults: the Third National Health and Nutrition Examination Survey, 1988-1994. Diabetes Care. 1998;21(4):518-524.

2. Nelson R, Everhart J, Knowler W, Bennett P. Incidence, prevalence and risk factors for non-insulin-dependent diabetes mellitus. Prim Care. 1988;15(2):227-250.

3. Katon W, Lin EH, Kroenke K. The association of depression and anxiety with medical symptom burden in patients with chronic medical illness. Gen Hosp Psychiatry. 2007;29(2):147-155.

4. Golden SH, Lazo M, Carnethon M, et al. Examining a bidirectional association between depressive symptoms and diabetes. JAMA. 2008;299(23):2751-2759.

5. Katon WJ. The comorbidity of diabetes mellitus and depression. Am J Med. 2008;121(11):S8-S15.

6. Eiber R, Berlin I, Grimaldi A, Bisserbe J. Insulin-dependent diabetes and psychiatric pathology: general clinical and epidemiologic review. L'Encephale. 1996;23(5):351-357.

7. Geffken GR, Ward HE, Staab JP, Carmichael SL, Evans DL. Psychiatric morbidity in endocrine disorders. Psychiatr Clin N Am. 1998;21(2):473-489.

8. Brown ES, Varghese FP, McEwen BS. Association of depression with medical illness: does cortisol play a role? Biol Psychiatry. 2004;55(1):1-9.

9. Lustman PJ, Griffith LS, Freedland KE, Clouse RE. The course of major depression in diabetes. Gen Hosp Psychiatry. 1997;19(2):138-143.

10. Lustman PJ, Griffith LS, Clouse RE, et al. Effects of nortriptyline on depression and glycemic control in diabetes: results of a double-blind, placebo-controlled trial. Psychosom Med. 1997;59(3):241-250.

11. Vamos EP, Mucsi I, Keszei A, Kopp MS, Novak M. Comorbid depression is associated with increased healthcare utilization and lost productivity in persons with diabetes: a large nationally representative Hungarian population survey. Psychosom Med. 2009;71(5):501-507.

12. Chen J-J, Liu Z, Fan S-H, et al. Combined application of NMR-and GC-MS-based metabonomics yields a superior urinary biomarker panel for bipolar disorder. Scientific Rep. 2014;4:5855.
13. Chen J-J, Huang H, Zhao L-B, et al. Sex-specific urinary biomarkers for diagnosing bipolar disorder. PloS One. 2014;9(12):e115221.

14. Yang J, Chen T, Sun L, et al. Potential metabolite markers of schizophrenia. Mol Psychiatry. 2013;18(1):67-78.

15. O'Kane M, Wiles P, Wales J. Fluoxetine in the treatment of obese type 2 diabetic patients. Diabet Med. 1994;11(1):105-110.

16. Gray D, Fujioka K, Devine W, Bray G. A randomized double-blind clinical trial of fluoxetine in obese diabetics. Int J Obes Relat Metab Disord: J Int Assoc Study Obes. 1992;16:S67-S72.

17. Levine L, Enas G, Thompson W, et al. Use of fluoxetine, a selective serotonin-uptake inhibitor, in the treatment of obesity: a dose-response study (with a commentary by Michael Weintraub). Int J Obes. 1988; 13(5):635-645.

18. Gülseren L, Gülseren S, Hekimsoy Z, Mete L. Comparison of fluoxetine and paroxetine in type II diabetes mellitus patients. Arch Med Res. 2005;36(2):159-165.

19. Paile-Hyvarinen M, Wahlbeck K, Eriksson JG. Quality of life and metabolic status in mildly depressed women with type 2 diabetes treated with paroxetine: a single-blind randomised placebo controlled trial. BMC Fam Pract. 2003;4:7.

20. Karaiskos D, Tzavellas E, Ilias I, Liappas I, Paparrigopoulos T. Agomelatine and sertraline for the treatment of depression in type 2 diabetes mellitus. Int J Clin Pract. 2013;67(3):257-260.

21. Cronk BC. How to Use SPSS: A Step-by-Step Guide to Analysis and Interpretation. Glendale, CA: Pyrczak Pub; 2004.

22. Miller GA, Chapman JP. Misunderstanding analysis of covariance. J Abnorm Psychol. 2001;110(1):40.

23. Goodnick PJ, Kumar A, Henry JH, Buki V, Goldberg RB. Sertraline in coexisting major depression and diabetes mellitus. Psychopharmacol Bull. 1996;33(2):261-264.

24. Lustman PJ, Freedland KE, Griffith LS, Clouse R. Fluoxetine for depression in diabetes: a randomized double-blind placebo-controlled trial. Diabet Care. 2000;23(5):618-623.

25. Paile-Hyvärinen M, Wahlbeck K, Eriksson JG. Quality of life and metabolic status in mildly depressed women with type 2 diabetes treated with paroxetine: a single-blind randomised placebo controlled trial. BMC Fam Pract. 2003;4(1):7.

26. Tamura Y, Tanaka Y, Sato F, et al. Effects of diet and exercise on muscle and liver intracellular lipid contents and insulin sensitivity in type 2 diabetic patients. J Clin Endocrin Metabol. 2005;90(6):3191-3196.

27. Kohen D, Burgess A, Catalan J, Lant A. The role of anxiety and depression in quality of life and symptom reporting in people with diabetes mellitus. Qual Life Res. 1998;7(3):197-204.

28. Petrak F, Herpertz S. Treatment of depression in diabetes: an update. Curr Opin Psychiatry. 2009;22(2):211-217.

29. Plesničar BK. Efficacy and tolerability of agomelatine in the treatment of depression. Pat Prefer Adher. 2014;8:603.

30. Gahr M. Agomelatine in the treatment of major depressive disorder: an assessment of benefits and risks. Curr Neuropharmacol. 2014;12(5): 387-398.

31. Ivanov SV, Samushiya MA. Agomelatine in the treatment of depressive disorders in clinical practice: multicenter observational CHRONOS study. Neuropsychiatr Dis Treat. 2014;10:631.
Neuropsychiatric Disease and Treatment

\section{Publish your work in this journal}

Neuropsychiatric Disease and Treatment is an international, peerreviewed journal of clinical therapeutics and pharmacology focusing on concise rapid reporting of clinical or pre-clinical studies on a range of neuropsychiatric and neurological disorders. This journal is indexed on PubMed Central, the 'PsycINFO' database and CAS,

\section{Dovepress}

and is the official journal of The International Neuropsychiatric Association (INA). The manuscript management system is completely online and includes a very quick and fair peer-review system, which is all easy to use. Visit http://www.dovepress.com/testimonials.php to read real quotes from published authors. 